\title{
Satisfaction with quality of healthcare at primary healthcare settings: Perspectives of patients with type 2 diabetes mellitus
}

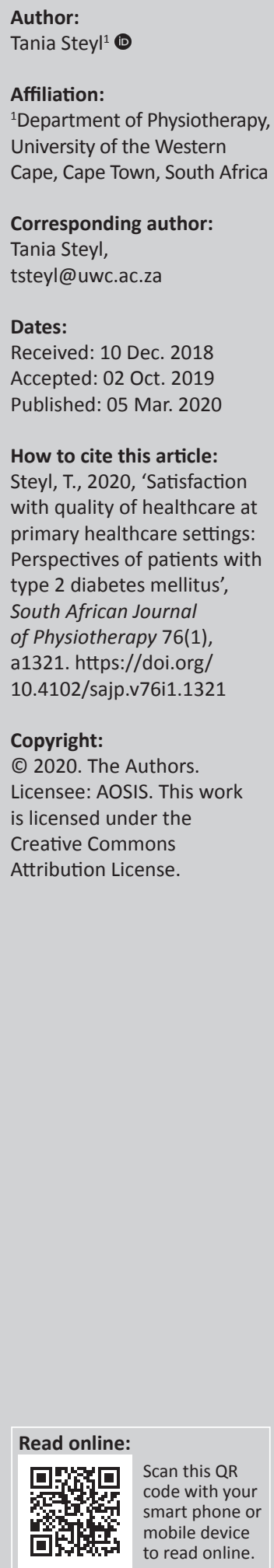

Background: Measuring client satisfaction is part of the quality assurance process and has become an integral part of healthcare management strategies globally. It is essential for improvement of amenities in healthcare facilities.

Objectives: The aim of this study was to assess patients with type 2 diabetes' satisfaction with healthcare services at primary healthcare settings in the Cape Metropolitan district, Western Cape, South Africa.

Methods: This cross-sectional study used proportionate stratified random sampling. The Patient Survey for Quality of Care scale was used to assess patients with type 2 diabetes' satisfaction with quality of care received. Descriptive and inferential statistics were employed in the analysis of the quantitative data. The open-ended question was analysed qualitatively.

Results: The majority of patients were satisfied with the overall quality of care. Dissatisfaction was reported for waiting time to get appointments at the clinic, to see a healthcare professional on the same day and clarity of instructions for managing their diabetes.

Conclusion: Employing more staff in the multidisciplinary team and improving health information by developing staff through continuous education could foster more positive experiences and provide care that contributes to the well-being of patients.

Clinical implications: Addressing patients' views regarding quality of healthcare services could assist in overall improvement of healthcare provision through the rectification of the system weaknesses. Satisfaction with quality of care could positively affect adherence to treatment protocols that could lead to better quality of life of patients with type 2 diabetes.

Keywords: quality of care; patient satisfaction; type 2 diabetes; primary healthcare; Western Cape; South Africa.

\section{Introduction}

Patient satisfaction is an important aspect of assessing the quality of patient care received at healthcare facilities globally (Al-Abri \& Al-Balushi 2014; Phaswana-Mafuya, Davids \& Senekal 2011; Sarkar \& Chatterjee 2011).

Patient perspectives about the level of care can result in feedback useful for promoting higher quality standards of patient care (Anhang et al. 2014). In Donabedian's (1988) quality measurement model, patient satisfaction is defined as a patient-reported outcome measure, while the structures and processes of care can be measured by patient-reported experiences (Oyvind, Ingeborg \& Hilde 2011). Measuring patient satisfaction is needed to ensure that health services address their needs (Fekadu, Andualem \& Yohannes 2011; Mosadeghrad 2014). The process is essential for the improvement of amenities in healthcare facilities (Al-Abri \& Al-Balushi 2014; Goldman, Vaiana \& Romley 2010).

The classic Quality of Care Framework consists of three elements: structures, process and health outcomes; the latter includes patients' satisfaction with healthcare services (World Health Organization [WHO] 2000).

The 2012 Institute of Medicine's landmark report, Crossing the Quality Chasm, expands the concept of the Quality of Care Framework to include six aims, namely, patient safety, effectiveness, patient centeredness, timelines, efficiency and equity (Peabody et al. 2006). A key element in the 
effectiveness of healthcare is the partnership between patients and healthcare providers (De Belvis et al. 2009; McGill \& Felton 2007; Nam et al. 2011). Measuring patients' satisfaction with services supports Donabedian's (1988) view of the patient as the ultimate authority. The patients' perceptions of their satisfaction with services provide information on whether the healthcare provider met their expectations (Donabedian 1988). Health-seeking behaviour and adherence to treatment decreases mortality, disability and healthcare costs, and are affected by patients' satisfaction with services (Shi 2012; Westaway et al. 2003). Valid and reliable health process measurement tools are available, but are not often utilised because of time constraints and inadequate staff numbers (Peabody et al. 2006).

The quality of healthcare services in most developing countries is often poor because of deficiencies in finance and resources (WHO 2000). Most healthcare facilities in sub-Saharan Africa lack healthcare professionals with specialised training in diabetes management, thus potentially compromising the quality of care for patients with this disease (Pastakia et al. 2017). Although a primary healthcare (PHC) approach was integrated into South Africa's National Health Act, 2004 (No. 61 of 2003), and operationalised through the district health service, the prevalence of diabetes mellitus is increasing at an alarming rate. Data from the World Health Organization indicate that $9.8 \%$ of South Africans aged 30 years and older have diabetes (WHO 2016). It is important to note that in 2010, the prevalence of type 2 diabetes in South Africa was estimated at $4.5 \%$ (IDF 2009). Thus, an alarming increase is reported in 6 years. Additionally, the reality of the situation is unknown as undiagnosed diabetes affects $84.4 \%$ of South Africans aged 20-79 years (IDF 2017). Not all PHC facilities in South Africa have specialised or formally organised diabetes healthcare delivery systems and inefficiently trained staff often manage patients with diabetes, thus compromising the quality of care of patients (Osei 2003).

Patient satisfaction is a key marker of communication and health-related behaviour (Tonio, Joerg \& Joachim 2011). Monitoring patients' perception is an important strategy to improve the performance of healthcare professionals.

Dissatisfaction with healthcare is associated with noncompliance of the treatment regimen and discontinuation of care (Krot \& Sousa 2017; Rama \& Kanagaluru 2011). Nonadherence, a characteristic of poor patient self-management, can increase mortality and disability, as well as healthcare costs (Currie et al. 2013). The process of providing care in developing countries is often poor and varies widely. Therefore, measuring client satisfaction should be at the forefront of all healthcare facilities.

The overall aim of my study was to assess patients with type 2 diabetes' satisfaction with healthcare services at PHC settings in the Cape Metropolitan district of the Western Cape, South Africa.

\section{Method}

This cross-sectional study was conducted on patients with type 2 diabetes from PHC facilities in the Cape Metropolitan district of the Western Cape, South Africa.

The study population consisted of all the patients diagnosed with type 2 diabetes mellitus at the community health centres (CHCs) in the Cape Metropolitan district at the time of data collection. Stratified random sampling was employed, the strata being the four sub-structures of the Cape Metropolitan district. To ensure equal representation from each substructure, random selection of $\mathrm{CHCs}$ was performed proportionately. One $\mathrm{CHC}$ was randomly selected from the following three sub-structures: Eastern and Khayelitsha subdistricts, Klipfontein and Mitchells Plain sub-districts, Northern and Tygerberg sub-districts and four CHCs from the Southern and Western sub-districts.

A total of seven $\mathrm{CHCs}$ were selected and included in the final sample. The Western Cape Department of Health, however, only gave ethical clearance and permission to conduct the study at six of the selected CHCs. The excluded $\mathrm{CHC}$ was inundated with research projects.

The sample size calculation was based on an estimated population, and at $95 \%$ confidence level; thus, 378 patients with type 2 diabetes were needed to participate in the study. At each $\mathrm{CHC}$, every second patient who visited the participating clinic for management of his or her disease was approached to participate in the study. Of the 420 patients who were approached, 384 consented and completed the questionnaire. However, 49 questionnaires were not included in the data analysis as they were incomplete. A response rate of $79.76 \%(n=335 / 420)$ was therefore achieved.

\section{Instrument}

Participants were given a modified self-administered questionnaire, based on existing valid and reliable scales.

The questionnaire consisted of two sections, namely, section 1: socio-demographic information and section 2: the patients' satisfaction with quality care questions and the quality of care scale (Woodward et al. 2000). The scale consists of 10 items with a five-point Likert scale ranging from poor to excellent ( 1 = poor, 2 = fair, 3 = good, $4=$ very good and $5=$ excellent $)$. Higher scores indicate more satisfaction with quality of care received at the $\mathrm{CHC}$. Three questions dichotomised into $0=$ no and $1=$ yes regarding the $\mathrm{CHC}$, as well as an openended statement for suggestions to improve services at the $\mathrm{CHC}$, were included.

A draft of the questionnaire, with all the sub-sections, was translated into isiXhosa and Afrikaans by independent healthcare professionals fluent in the respective languages. The translated questionnaires were then back-translated into English by a linguist in Afrikaans and isiXhosa, respectively. The questionnaires (English, Afrikaans and isiXhosa versions) 
were administered to a sub-sample of 15 patients with type 2 diabetes mellitus who were not included in the study to assess the face validity and applicability of all the items for this population, its level of understandability and the time it would take to be completed. A 30-min focus group discussion followed the completion of the questionnaire to test the content validity of the instrument and to see whether it was necessary to rephrase or change any of the questions. Only a few grammatical changes were made. The results indicated that the instrument was relevant to the population and was easily used by the patients. The final questionnaire was sent to experts in the field of management of diabetes and chronic diseases of lifestyle to analyse the items to see if they adequately represented the hypothetical content in the correct proportions. No changes were suggested.

To test reliability, the same questionnaire was administered 2 weeks later to the same sub-sample of 15 patients. Testretest reliability was measured using a correlation coefficient. According to Nunnally and Bernstein (1994), an Intraclass correlation coefficient (ICC) of above 0.81 is considered almost perfect agreement; between 0.61 and 0.80 , it indicates substantial agreement; between 0.41 and 0.60 , it indicates moderate agreement; between 0.21 and 0.40 , it indicates fair agreement; and below 0.20 , it indicates poor agreement. The internal consistency of the English, Afrikaans and isiXhosa versions of the translated questionnaires yielded the following scores: $0.748,0.833$ and 0.790 , respectively. All the sub-scales, except for the English and isiXhosa versions of the 'knowledge of diet' sub-scale, had substantial to almost perfect agreement, indicating good stability.

\section{Data collection}

Data were collected for a period of 6 months, from January to June 2012. After ethical clearance was obtained from all relevant authorities, written informed consent was sought from the 420 patients who were approached to participate in the study. A total of 384 patients consented, while 36 patients refused to participate in the study. The final sample was 335 adult patients with type 2 diabetes mellitus as 49 questionnaires were excluded because of missing data.

Each participant was invited to go to a private room where the anthropometric measurements and blood pressure were taken. The rest of the questionnaire was then completed in the waiting room of the healthcare facility in the presence of the research assistant.

\section{Data analysis}

Data were captured on a 2010 Word Excel spreadsheet and imported into the Statistical Package for the Social Sciences (SPSS) version 21.0 for analysis. Descriptive statistics were employed to summarise the socio-demographic data. Inferential statistics (cross tabulations) were used to determine the pattern of distribution in the various groups. Significant differences were tested using the Fisher's exact test of independence. Statistical significance was set at a $p$-value of less than 0.05 .

The open-ended questions were analysed qualitatively. Content analysis was performed by extracting meaningful ideas of the participants' opinions and grouping them into categories. Then the author looked for emerging themes. After the derivation of themes, an independent researcher read through the transcripts and generated themes that were then compared with the themes of the author.

\section{Ethical considerations}

Permission and ethical clearance were obtained from the Senate Research Grants and Study Leave Committee at the University of the Western Cape (UWC) (Reference number $11 / 4 / 2)$. Further permission was obtained from the Western Cape Department of Health (2011/07/14; Reference number RP59/2011) and the facility managers of the participating CHCs. The following guidelines were followed:

The consent forms, information sheets and questionnaires were available in Afrikaans, English and isiXhosa.

Signed, written informed consent was sought from all the participants before their participation in the study.

\section{Results}

A total of 335 patients (119 men [35.5\%] and 216 women [64.5\%] with a mean age of 58.25 [ \pm 10.58 years]) completed the Patient Survey for Quality of Care scale. The participants were predominantly $(48.4 \%)$ from a mixed race population group. The majority were 50 years and older (81.2\%).

Of the participants, $57 \%$ were married or had a domestic partner, while half of the participants' (50.1\%) highest level of education was primary school. Participants were asked about where they live most of the year, to which $55.5 \%$ reported that they live in their own home or flat, while $39.7 \%$ reported they lived with friends or family. More than one-third (37.7\%) of the participants were unemployed, while $33.1 \%$ were pensioners.

For the purpose of this study, satisfaction was classified as the sum of good, very good and excellent responses and not satisfied was classified as the sum of poor and fair responses. From the data in Table 1, the majority of respondents $(78.5 \%)$ were satisfied that clinic staff gave clear and complete explanations of medical information. They felt that the staff were concerned and caring (77\%) and that their personal safety and their belongings were assured (81.2\%). Most of the participants $(89.2 \%)$ were satisfied with the level of privacy and the overall quality of care $(80.9 \%)$ provided by the healthcare facility. However, just over half of the respondents were satisfied with the waiting time to get an appointment $(52.5 \%)$. More than two-thirds of the respondents were not satisfied with waiting time in the clinic room to see a healthcare professional (65.3\%); the instructions 
that were given by clinic staff to prepare for the next visit $(69.6 \%)$ as well as clarity of instructions to manage their diabetes at home $(65.9 \%)$.

Fisher's exact test of independence was conducted to compare the statements or items for satisfaction with quality care for men and women. No significant gender differences were found on any of the satisfaction with quality of care outcomes $(p>0.05)$ (Table 2).

Responses to the three validity items indicated that only a few patients felt that they were asked to leave the clinic before they felt ready to do so $(n=9,2.7 \%)$. Forty-two respondents $(12.5 \%)$ stated that they sought medical attention as a result of the services rendered at the $\mathrm{CHC}$, while only five $(1.5 \%)$ stated they would not recommend the clinic to family and friends if they were in need of such services.

Table 3 summarises the responses to an open-ended question regarding their suggestions about any improvement of services at the CHCs. Only $37(11.0 \%)$ participants responded to this question. The identified themes included staff concerns, concerns of time and communication issues.

With regard to staff concerns, almost all the patients suggested that more staff is needed or should be made available to them in general, especially an increased availability of doctors

TABLE 1 : Satisfaction with the quality care scores of patients with type 2 diabetes mellitus $(n=335)$

\begin{tabular}{|c|c|c|c|c|c|c|c|c|c|c|}
\hline \multirow[t]{2}{*}{ Statement } & \multicolumn{2}{|c|}{ Poor } & \multicolumn{2}{|c|}{ Fair } & \multicolumn{2}{|c|}{ Good } & \multicolumn{2}{|c|}{ Very good } & \multicolumn{2}{|c|}{ Excellent } \\
\hline & $n$ & $\%$ & $n$ & $\%$ & $n$ & $\%$ & $n$ & $\%$ & $n$ & $\%$ \\
\hline Waiting time to get an appointment & 29 & 8.7 & 130 & 38.8 & 169 & 50.4 & 7 & 2.1 & - & - \\
\hline Waiting time in clinic room to see a health care professional & 51 & 15.2 & 168 & 50.1 & 112 & 33.4 & 4 & 1.2 & - & - \\
\hline Instructions given by clinic staff to prepare you for the visit & 77 & 23.0 & 156 & 46.6 & 98 & 29.3 & 4 & 1.2 & - & - \\
\hline Ease of getting information from clinic staff & 18 & 5.4 & 110 & 32.8 & 194 & 57.9 & 13 & 3.9 & - & - \\
\hline Clear and complete explanations on information given by clinic staff & 3 & 0.9 & 69 & 20.6 & 240 & 71.6 & 23 & 6.9 & - & - \\
\hline Concern and caring by clinic staff & 5 & 1.5 & 72 & 21.5 & 168 & 50.1 & 90 & 26.9 & - & - \\
\hline Safety and security of you and belongings & 6 & 1.8 & 57 & 17.0 & 177 & 52.8 & 95 & 28.4 & - & - \\
\hline Privacy & 3 & 0.9 & 33 & 9.9 & 187 & 55.8 & 112 & 33.4 & - & - \\
\hline Clarity of instructions upon leaving & 53 & 15.8 & 168 & 50.1 & 99 & 29.6 & 15 & 4.5 & - & - \\
\hline Overall quality care & 4 & 1.2 & 60 & 17.9 & 217 & 64.8 & 54 & 16.1 & - & - \\
\hline
\end{tabular}

TABLE 2: Gender differences in satisfaction with the quality care statements of patients with type 2 diabetes mellitus ( $n=335$ )

\begin{tabular}{|c|c|c|c|c|c|c|c|c|c|c|c|c|c|}
\hline \multirow[t]{2}{*}{ Statement } & \multicolumn{2}{|c|}{ Gender } & \multicolumn{2}{|c|}{ Poor } & \multicolumn{2}{|c|}{ Fair } & \multicolumn{2}{|c|}{ Good } & \multicolumn{2}{|c|}{ Very good } & \multicolumn{2}{|c|}{ Excellent } & \multirow[t]{2}{*}{$P$-value } \\
\hline & $n$ & $\%$ & $n$ & $\%$ & $n$ & $\%$ & $n$ & $\%$ & $n$ & $\%$ & $n$ & $\%$ & \\
\hline Waiting time to get an appointment & & & & & & & & & & & & & 0.672 \\
\hline Male & 119 & 35.5 & 9 & 7.6 & 49 & 41.2 & 60 & 50.4 & 1 & 0.8 & - & - & - \\
\hline Female & 216 & 64.5 & 20 & 9.3 & 81 & 37.5 & 109 & 50.5 & 6 & 2.7 & - & - & - \\
\hline Waiting time in clinic room to see a health care professional & & & & & & & & & & & & & 0.055 \\
\hline Male & - & - & 12 & 10.1 & 69 & 58.0 & 38 & 31.9 & - & - & - & - & - \\
\hline Female & - & - & 39 & 18.1 & 99 & 45.7 & 74 & 34.3 & 4 & 1.9 & - & - & - \\
\hline Instructions given by clinic staff to prepare you for the visit & & & & & & & & & & & & & 0.983 \\
\hline Male & - & - & 27 & 22.7 & 57 & 47.9 & 34 & 28.6 & 1 & 0.08 & - & - & - \\
\hline Female & - & - & 50 & 23.2 & 99 & 45.8 & 64 & 29.6 & 3 & 1.4 & - & - & - \\
\hline Ease of getting information from clinic staff & & & & & & & & & & & & & 0.379 \\
\hline Male & - & - & 3 & 2.5 & 39 & 32.8 & 72 & 60.5 & 5 & 4.2 & - & - & - \\
\hline Female & - & - & 15 & 6.9 & 110 & 32.9 & 112 & 56.5 & 8 & 3.7 & - & - & - \\
\hline Clear and complete explanations on information given by clinic staff & & & & & & & & & & & & & 0.658 \\
\hline Female & - & - & 3 & 1.4 & 46 & 21.3 & 151 & 69.9 & 16 & 7.4 & - & - & - \\
\hline Concern and caring by clinic staff & & & & & & & & & & & & & 0.338 \\
\hline Male & - & - & - & - & 24 & 20.2 & 59 & 49.6 & 36 & 30.2 & - & - & - \\
\hline Female & - & - & 5 & 2.3 & 48 & 22.2 & 168 & 50.5 & 54 & 25.0 & - & - & - \\
\hline Safety and security of you and belongings & & & & & & & & & & & & & 0.333 \\
\hline Male & - & - & 1 & 0.8 & 16 & 13.4 & 70 & 67.2 & 32 & 26.6 & - & - & - \\
\hline Female & - & - & 5 & 2.3 & 41 & 19.0 & 107 & 49.5 & 63 & 29.2 & - & - & - \\
\hline Privacy & & & & & & & & & & & & & 0.302 \\
\hline Male & - & - & - & - & 8 & 6.7 & 71 & 56.7 & 40 & 33.6 & - & - & - \\
\hline Female & - & - & 3 & 1.4 & 25 & 11.6 & 116 & 53.7 & 72 & 33.3 & - & - & - \\
\hline Clarity of instructions upon leaving & & & & & & & & & & & & & 0.555 \\
\hline Male & - & - & 15 & 12.6 & 62 & 52.1 & 38 & 31.9 & 4 & 3.4 & - & - & - \\
\hline Female & - & - & 38 & 17.6 & 106 & 49.1 & 61 & 28.2 & 11 & 5.1 & - & - & - \\
\hline Overall quality care & & & & & & & & & & & & & 0.883 \\
\hline
\end{tabular}


TABLE 3: Summary to open-ended question: Any suggestions for improvement of services at the $\mathrm{CHC}(n=37)$

\begin{tabular}{llcc}
\hline Main themes & Categories & $\boldsymbol{n}$ & $\mathbf{\%}$ \\
\hline Staff concerns & More staff needed/available in general, especially & 35 & 94.6 \\
& $\begin{array}{l}\text { increased availability of doctors } \\
\end{array}$ & & \\
& More staff working in the pharmacy of the CHC & 13 & 35.1 \\
& Doctors spending more time with a patient & 22 & 59.5 \\
& More friendly and helpful nursing/administrative staff & 26 & 70.3 \\
Concerns of & Shorter waiting period for an appointment & 17 & 46.0 \\
time & Shorter waiting time at the CHC in general & 21 & 56.6 \\
& Shorter waiting time at the pharmacy & 33 & 89.6 \\
& Longer business hours & 16 & 43.2 \\
Communication & More accurate instructions while at the clinic & 11 & 29.7 \\
issues & More accurate instructions when leaving & 19 & 51.4 \\
& More feedback and communication from the doctor & 31 & 83.8 \\
& Better telephonic access to information needed & 14 & 37.8 \\
\hline
\end{tabular}

$\mathrm{CHC}$, community health centre

$(n=35,94.6 \%)$. Other staff concerns raised were more staff working in the pharmacy of the CHC $(n=13,35.1 \%)$, doctors spending more time with patients $(n=22,59.5 \%)$ as well as more friendly and helpful nursing or administrative staff $(n=26,70.3 \%)$.

Suggestions for time concerns included a shorter waiting period for an appointment $(n=17,46.0 \%)$ and waiting time at the CHC $(n=21,56.6 \%)$ in general as well as at the pharmacy $(n=33,89.2 \%)$. Longer business hours $(n=16,43.2 \%)$ were also recommended.

Patients advised that communication issues should be addressed as follows: more accurate instructions while at the clinic ( $n=11,29.7 \%)$ as well as when leaving $(n=19,51.4 \%)$, more feedback and communication from the doctor $(n=31,83.8 \%)$ as well as better telephonic access to information regarding their health concerns $(n=14,37.8 \%)$.

\section{Discussion}

The results of this study should be interpreted with caution as they may tend to exaggerate social desirability which may lead to bias. The difference in satisfaction amongst different studies can be attributed to different settings, study participants (not only patients with chronic illnesses) and methodologies employed. The overall level of satisfaction with the healthcare of the patients attending PHC settings in the Cape Metropolitan district of the Western Cape, South Africa, was $80.9 \%$. This finding is similar to a study conducted in Majmaah, Saudi Arabia, where an $81.7 \%$ level of satisfaction with healthcare was reported (Mohamed et al. 2015). This study revealed much higher satisfaction with healthcare compared to findings from studies conducted in the United Kingdon (UK), India, Kosovo, Iraq and Botswana where levels of $61.3 \%, 66 \%, 73.5 \%, 50.9 \%$ and $57.1 \%$ were reported, respectively (AbdSa'adoon, Hussien \& Museher 2008; Abiodun 2013; Raghunath, Vijayalakshmi \& Sathagurunath 2013; Tahiri et al. 2014; Wetmore et al. 2014).

More than three quarters $(78.5 \%)$ of the patients were satisfied with the provision of information about their health problems, which is similar to the findings of Bamidele,
Hoque and Van der Heever (2011), Fekadu et al. (2011) as well as a study conducted in Swedish PHC settings (Johansson, Bendtsen \& Akerlin 2005). Despite the patients' high ranking of provision of information, many healthcare professionals still struggle to fully understand patients' information needs (Wadhwa 2002). This author furthermore stated that if healthcare professionals do not provide the correct information regarding the patient's disease and its management, it could negatively impact patient's perception of the quality of care received (Wadhwa 2002). Effective communication and clear explanations have the strongest impact in improving overall patient satisfaction amongst other attributes of care (John, Anne \& Austin 2003). This finding provides evidence of the importance of the role of communication as a significant determinant of overall patient satisfaction. Interpersonal communication skills of healthcare professionals in terms of their attitude, explanation of conditions, emotional support and involving patients in decision-making are also found to influence patient satisfaction (Andrabi et al. 2012).

This study reported a high satisfaction rate for privacy $(89.2 \%)$, which is higher than the $69 \%$ of participants who were satisfied with the privacy in hospital (Fekadu et al. 2011). Dissatisfaction with privacy was also reported in studies conducted in India (Kumari et al. 2009) and Bangladesh (Mendoza, Piechulek \& Al-Sabir 2001). The higher satisfaction rate of this study could be attributed to the research setting. Patients are seen by the healthcare professionals in a confined private space, while the environment of a tertiary hospital is less conducive to privacy. Most of the rooms in a tertiary hospital are four- or six-bed rooms, with healthcare professionals providing their services at the bedside. All the other patients in the room can thus hear conversations between patients and healthcare professionals.

Waiting time - to get an appointment at the $\mathrm{CHC}$, the time to see a healthcare professional or the time a healthcare professional spends during the visit - was of concern for these participants.

Fifty-three per cent of patients were dissatisfied by the overall waiting time to get an appointment as well as the time spent at the CHC. The percentage dissatisfaction is $63.9 \%$ reported in a study conducted in Botswana (Bamidele et al. 2011). Waiting time is a cause of frustration for patients and remains a challenge to the quality of care and services in clinics (McCarthy, McGee \& O'Boyle 2004). Although only $37.0 \%$ of the participants in the Ethiopian study of Fekadu et al. (2011) reported dissatisfaction with waiting time, the authors noted that the 'time factor' (time spent on scheduling and waiting time in the clinic) significantly correlated with overall satisfaction.

Satisfaction was also inversely related with waiting time in studies from India (Kumari et al. 2009) and Bangladesh (Mendoza et al. 2001). The major dissatisfaction in out-patient departments at tertiary hospitals is the long waiting time and overcrowded registration (Arshad et al. 2012; Bakshi 2013). 
Eighty-seven per cent of patients in PHC settings in Kuwait reported that the communication time between doctors and patients is insufficient (Alhashem, Alquraini \& Chowdhury 2011). If enough time is spent with the doctor and the patient's questions and concerns are addressed, it can lead to a greater belief that the diagnosis and treatment must be correct (Otani, Kurz \& Harris 2005). This aspect of care should thus receive careful attention in efforts to improve patient satisfaction. In addition, the dissatisfaction rate with time in this study could be because of the low number of healthcare professionals working at the $\mathrm{CHC}$, hence the higher healthcare professional or patient ratio and patient load.

No significant associations were found between sociodemographic characteristics such as educational status, age, gender and patients' perceptions of the quality of diabetes care. However, male participants were more satisfied than female participants with the overall quality of care. In a Turkish study, income level (high), marital status (married) and occupation (high level of education) were found to be significant predictors of satisfaction of care (Baltaci et al. 2013). However, Mohamed et al. (2015) and Fekadu et al. (2011) report that patients who are illiterate or have a low level of education and those from an older age group are more satisfied compared to those who have tertiary education and who are from a younger age group, respectively.

\section{Practical implications}

A better appreciation of the factors pertaining to patient satisfaction with quality of healthcare could result in implementation of plans more appropriate for the requirements of patients. Patients are the best arbiters of services because they accurately assess the services provided and their input can help in the overall improvement of healthcare provision. These study results are important considerations for the management of healthcare services to develop policies and strategies for improving the quality of healthcare.

\section{Limitations of the study}

Data were based on self-report; thus, the findings are subject to desirability and recall bias. Although the baseline data of the study were collected from six randomly selected CHCs in the Cape Metropolitan district of the Western Cape, only 37 of the 335 participants completed the open-ended questions. The responses may not be representative of the general population of individuals with type 2 diabetes mellitus. Therefore, generalisation of the findings to other areas is limited.

\section{Conclusion}

The results of this study showed that participants were satisfied with the quality of care provided by the different service providers of the healthcare facility in the Western Cape. There is a need for interventions in terms of time spent at the facility, staff shortage and telephonic access to health outcomes. Such interventions could promote good clientcentred service delivery, which could aid in preserving and promoting the well-being and quality of life of patients with type 2 diabetes. The Department of Health's policy on quality in healthcare (Department of Health 2007) and the South African 2014/2015 Health Review reiterate that public services need to respond to patients' requests and expectations. It is important that the relevant authorities address the shortages of staff at PHC facilities in the Western Cape. The feedback from patient satisfaction surveys could assist with improved prioritisation and allocation of resources and it could also serve as a platform for providing better services.

\section{Acknowledgements Competing interests}

The author has declared that no competing interest exists.

\section{Authors' contributions}

I declare that I am the sole author of this article.

\section{Funding information}

This research received no specific grant from any funding agency in the public, commercial, or not-for-profit sectors.

\section{Data availability statement}

Data sharing is not applicable to this article as no new data were created or analysed in this study.

\section{Disclaimer}

The views and opinions expressed in this article are those of the author and do not necessarily reflect the official policy or position of any affiliated agency of the author.

\section{References}

AbdSa'adoon, A., Hussien, A.H. \& Museher, T.R., 2008, 'Patients' satisfaction for health care services at Thi-qar province', Iraq Thi-Qar Medical Journal 2(1), 39-45.

Abiodun, A.J., 2013, 'Patients' satisfaction with quality attributes of primary health care services in Botswana', Journal of Health Management 12(1), 39-54. https:// doi.org/10.1177/097206340901200104

Al-Abri, R. \& Al-Balushi, A., 2014, 'Patient satisfaction survey as a tool towards quality improvement', Oman Medical Journal 29(1), 3-7. https://doi.org/10.5001/ omj.2014.02

Alhashem, A.M., Alquraini, H. \& Chowdhury, R.I., 2011, 'Factors influencing patient satisfaction in primary healthcare clinics in Kuwait', International Journal of Health Care Quality Assurance 24(3), 249-262. https://doi.org/10.1108/0952686 1111116688

Andrabi, S.A., Hamid, S., Rohul J. \& Anjum, F., 2012, 'Measuring patient satisfaction: A cross sectional study to improve quality of care at a tertiary care hospital', Health Line 3(1), 59-62.

Anhang, P.R., Elliott, M.N., Zaslavsky, A.M., Hays, R.D., Lehrman, W.G., Rybowski, L. et al., 2014, 'Examining the role of patient experience surveys in measuring health care quality', Medical Care Research and Review 71(5), 522-554. https://doi. org/10.1177/1077558714541480

Arshad, S., Andrabi, H., Hamid, S. \& Masooda, S., 2012, 'Measuring patients satisfaction: A cross sectional study to improve quality of care at a tertiary care hospital', East African Journal of Public Health 9(1), 26-28.

Bakshi, S.M., 2013, 'A study of patient satisfaction at a tertiary care hospital in Hyderabad, India', World Hospitals and Health Services 49(2), 26-29.

Baltaci, D., Eros, R., Ankarali, H. \& Erdem, O., 2013, 'Association between patients' sociodemographic characteristics and their satisfaction with primary health care services in Turkey', Kuwait Medical Journal 45(4), 291-299. 
Bamidele, A.R., Hoque., M.E. \& Van der Heever, H., 2011, 'Patient satisfaction with quality of care in a primary health care setting in Botswana', South African Journal of Family Practice 53(2), 170-175. https://doi.org/10.1080/20786204.2011.1087 4080

Currie, C.J., Peyrot, M., Morgan, C.L., Poole, C.D., Jenkins-Jones, S., Rubin, R.R. et al. 2013 , 'The impact of treatment non-compliance on mortality in people with type 1 diabetes', Journal of Diabetes and Its Complications 27(3), 219-223. https://doi org/10.1016/j.jdiacomp.2012.10.006

Department of Health, 2007, A policy in quality of health care in South Africa, viewed 14 August 2018, from https://www.cohsasa.co.za/sites/cohsasa.co.za/ files/publication_pdfs/qhc.pdf.

De Belvis, A.G., Pelone, F., Biasco, A., Ricciardi, W. \& Volpe, M., 2009, 'Can primary care professionals' adherence to evidence based medicine tools improve quality of care in type 2 diabetes mellitus? A systematic review', Diabetes Research and Clinical Practice 85(2), 119-131. https://doi.org/10.1016/j. diabres.2009.05.007

Donabedian, A., 1988, 'The quality of care. How can it be assessed?', The Journal of the American Medical Association 260(12), 1743-1748. https://doi.org/10.1001/ jama.260.12.1743

Fekadu, A., Andualem, M. \& Yohannes, M., 2011, 'Assessment of clients' satisfaction with health service deliveries at Jimma University Specialized Hospital', Ethiopian Journal of Health Sciences 21(2), 101-109. https://doi.org/10.4314/ ejhs.v21i2.69050

Goldman, D.P, Vaiana, M. \& Romley, J.A., 2010, 'The emerging importance of patient amenities in hospital care', The New England Journal of Medicine 363(23) 2185-2187. https://doi.org/10.1056/NEJMp1009501

Institute of Medicine, 2001, Crossing the quality chasm, National Academy Press, Washington, DC.

International Diabetes Federation (IDF), 2009, IDF diabetes atlas, 4th edn., IDF, Brussels. International Diabetes Federation (IDF), 2017, IDF diabetes atlas, 8th edn., IDF, Brussels.

Johansson, K., Bendtsen, P. \& Akerlin, I., 2005, 'Advice to patients in Swedish primary care regarding alcohol and other lifestyle habits: How patients report the actions of GPs in relation to their own expectations and satisfaction with the consultation' European Journal of Public Health 15(6), 615-620. https://doi.org/10.1093/ eurpub/cki046

John, S., Anne, M.B. \& Austin, L., 2003, 'Development of the Irish national patien perception of quality of care', International Journal for Quality Health Care 15(2), 163-168. https://doi.org/10.1093/intqhc/mzg022

Kumari, R., Idris, M., Bhushan, V., Khanna, A., Agarwal, M. \& Singh, S., 2009, 'Study on patient satisfaction in the government allopathic health facilities of Lucknow district, India', Indian Journal of Community Medicine 34(1), 35-42. https://doi. org/10.4103/0970-0218.45372

Krot, K. \& Sousa, J.P., 2017, 'Factors impacting on patient compliance with medical advice: Empirical study', Engineering Management in Production and Services 9(2), 73-81. https://doi.org/10.1515/emj-2017-0016

Mendoza, A.J., Piechulek, H. \& Al-Sabir, A., 2001, 'Client satisfaction and quality of health care in rural Bangladesh', Bulletin of the World Health Organization 79(6), 512-517.

McCarthy, K., McGee, H.M. \& O'Boyle, C.A., 2004, 'Outpatient clinic waiting times and non-attendance as indicators of quality', Psychology, Health and Medicine 5(3), 287-93. https://doi.org/10.1080/713690194

McGill, M. \& Felton, A., 2007, 'New global recommendations: A multidisciplinary approach to improving outcomes in diabetes', Primary Care Diabetes 1(1), 49-55. https://doi.org/10.1016/j.pcd.2006.07.004

Mohamed, E.Y., Sami, W., Alotaibi, A., Alfarag, A., Almutairi, A. \& Alanzi, F., 2015 'Patients' satisfaction with primary health care centers' services, Majmaah, Kingdom of Saudi of Saudi Arabia', International Journal of Health Sciences 9(2), 163-70. https://doi.org/10.12816/0024113

Mosadeghrad, M.A., 2014, 'Factors influencing healthcare service quality', International Journal of Health Policy and Management 3(2), 77-89. https://doi. org/10.15171/ijhpm.2014.65

Nam, S., Chesla, C., Stotts, N.A., Kroon, L. \& Janson, S.L., 2011, 'Barriers to diabetes management: Patient and provider factors', Diabetes Research and Clinical Practice 93(1), 1-9. https://doi.org/10.1016/j.diabres.2011.02.002
Nunnally, J.C. \& Bernstein, I.H., 1994, Psychometric theory, 3rd edn., McGraw-Hill, New York.

Osei, K., 2003, 'Global epidemic of type 2 diabetes: Implication for developing countries', Ethnic Disease 13(2), 102-106.

Otani, K., Kurz, R.S. \& Harris, L.E., 2005, 'Managing primary care using patient satisfaction measures', Journal of Healthcare Management 50(5), 311-324. https://doi.org/10.1097/00115514-200509000-00007

Oyvind, A.B., Ingeborg, S.S. \& Hile, H.I., 2011, 'Overall patient satisfaction with hospitals: Effects of patient-reported experiences and fulfilment of expectations' British Medical Journal Quality Safety 21, 39-46. https://doi.org/10.1136/ bmjqs-2011-000137

Pastakia, S.D., Pekny, C.R., Manyara, S.M. \& Fischer, L., 2017, 'Diabetes in sub-Saharan Africa - from policy to practice to progress: Targeting the existing gaps for future care for diabetes', Diabetes, Metabolic Syndrome and Obesity: Targets and Therapy 10, 247-263. https://doi.org/10.2147/DMSO.S126314

Peabody, J.W., Taguiwalo, M.M., Robalino, D.A. \& Frenk, J., 2006, 'Improving the quality of care in developing countries', in D.T. Jamison, J.G. Breman, A.R Measham, G. Alleyne, M. Claeson, D.B. Evans et al. (eds.), Disease control prioritie in developing countries, pp. 1293-1308, 2nd edn., Oxford University Press, New York.

Phaswana-Mafuya, N., Davids, A.S. \& Senekal, S.M., 2011, 'Patient satisfaction with primary health care services in a selected municipality of the Eastern Cape, South Africa', in A.B. Eldin (ed.), Modern approached to quality control, IntechOpen, London.

Raghunath, E., Vijayalakshmi, S. \& Sathagurunath, P.A, 2013, 'Satisfaction at primary health centers in Puducherry', The Health Agenda 1(4), 1-4.

Rama, M. \& Kanagaluru, S.K., 2011, 'A study on the satisfaction of patients with reference to hospital services', International Journal of Business Economics \& Management Research 1(3), 15-25. https://zenithresearch.org.in/.

Sarkar, J. \& Chatterjee, B., 2011, 'An experience of health services provided by a peripheral government teaching hospital in India: Patients' perspective', Indian Journal of Medical Sciences 65(8), 321-330. https://doi.org/10.4103/00195359.107768

Shi, L., 2012, 'The impact of primary care: A focused review', Scientifica 2012:432892, 22 pages. https://doi.org/10.6064/2012/432892

South African Health Review 2014/2015, viewed 19 September 2018, from https://www.health-e.org.za/wp-content/uploads/2015/10/HST-SAHR-2014-15 Complete.pdf.

Tahiri, Z., Toçi, E., Rrumbullaku, L., Hoti, K., Roshi, E. \& Burazeri, G., 2014, 'Patients' evaluation of primary health care services in Gijlan region', Kosovo Journal of Public Health 36(1), 161-169. https://doi.org/10.1093/pubmed/fdt041

Tonio, S. Joerg K. \& Joachim, K. 2011, 'Determinants of patient satisfaction: A study among 39 hospitals in an in-patient setting in Germany', International Journal for Quality in Health Care 23(5), 503-509. https://doi.org/10.1093/ Journal for Qu
intahc/mzr038

Wadhwa, S.S., 2002, 'Customer satisfaction and health care delivery system: Commentary with Australian bias', The Internet Journal of Nuclear Medicine 1(1). https://www.ispub.com/ostia/index.php?xmlFilePath=journals/ijh/vol3n1/ $1(1)$. https:/
bias.xml.

Westaway, M.S., Seager, J.R., Rheeder, P. \& Van Zyl, D.G., 2003, 'The effects of social support on health, well-being and management of diabetes mellitus: A black South African perspective', Ethnicity and Health 10(1), 73-89. https://doi.org/ 10.1080/1355785052000323047

Wetmore, S., Boisvert, L., Graham, E., Hall, S., Hartley, T., Wright, L. et al. 2014, 'Patient satisfaction with access and continuity of care in a multidisciplinary academic family medicine clinic', Canadian Family Physician 60(4), e231-e236.

Woodward, C.A., Ostbye, T., Craighead, J., Gold, G. \& Wenghofer, E.F., 2000, 'Patient satisfaction as an indicator of quality care in independent health facilities: Developing and assessing a tool to enhance public accountability', American Journal of Medical Quality 15(3), 94-105. https://doi.org/10.1177/10628606000 1500303

World Health Organization (WHO), 2000, World health report 2000. Health systems: Improving performance, WHO, Geneva.

World Health Organization (WHO), 2016, Diabetes country profiles 2016, viewed 15 October 2018, from https://www.who.int/diabetes/country-profiles/zaf_en.pdf. 